\title{
Ricardo Latcham en la crítica de América Hispana
}

C ON extraña proximidad de fechas han desaparecido algunas de las figuras más activas del ensayo y la crítica actuales de América Hispana. Primero fue el argentino Ezequiel Martínez Estrada, uno de los más penetrantes auscultadores del alma rioplatense, sobre todo en su señero ensayo Radiografía di la Pampa (1933); luego, al filo del presente año y en rápida sucesión, dos amigos entrañables, el chileno Ricardo Latcham y el venezolano Mariano Picon-Salas, ágil estudioso y sistematizador de aspectos decisivos del desenvolvimiento literario e histórico hispanoamericano, como se revela en su De la Conquista a la Independencia ( I944).

Los tres críticos y ensayistas fallecidos provienen de la alta disciplina estético científica inaugurada entre nosotros por el dominicano Pedro Henríquez Ureña y el mexicano Alfonso Reyes, en torno a cuyos impulsos renovadores se congregó el brillante grupo de hombres de letras nacidos en las inmediaciones de I900, entre los cuales no pueden dejar de citarse a Jorge Mañach, Arturo Torres-Rioseco, Julio Martínez Rueda, Juan Marinello, Jorge Luis Borges, Germán Arciniegas, Luis Emilio Soto, Guillermo Francovich, Luis Alberto Sánchez, Carlos Alberto Erro, Eduardo Mallea, Concha Meléndez, Arturo Uslar Pietri, Raimundo Lida, Enrique Anderson-Imbert, José Antonio Portuondo.

Es indudable que a estos hombres y a sus páginas - nómina muy lejos de ser completa - se encuentra íntimamente vinculado el momento más fecundo en anhelos del proceso literario hispanoamericano contempo. ráneo, aquél que determina la plenitud del criollismo y su liquidación, la consiguiente transfiguración de la herencia simbolista y que, finalmente, configura las modernas perspectivas creadoras de la poesía, el relato, el teatro y el ensayo en las letras continentales. 
La responsabilidad del crítico llamado a prestar un apoyo efectivo al escritor y una posición adecuada al lector fue revistiendo, en el panorama cultural del continente, una complejidad cada vez mayor, en especial después de la segunda década del siglo. La multiplicidad de corrientes vanguardistas originadas en el fondo modificador establecido tan vigorosamente por el expresionismo y las diversas modalidades del posmodernismo, desataron en el ámbito de la cultura universal una actividad publicitaria y editorial y un tráfico de ideas que no era fácil absorber y asimilar, y crearon un momento de confusión en que el arte parecía también atrapado por los mismos tentáculos que motivaron la estrangulación economicosocial de r929. Su destino parecía, pues, sujeto al dictamen de cualquier aventura más o menos ingeniosa y audaz.

Tal apariencia engañosa vino a desvanecerse sólo por el año I930. La empresa de clarificación y sistematización teórica - iniciada entoncesestuvo a cargo de la acción ejercida por la llamada generación hispanoamericana del '3c, desde la cátedra, la prensa y el libro. A esta agrupación de intelectuales se adscribe cabalmente el crítico chileno Ricardo Latcham.

Tanto por las circunstancias de servir una cátedra de literatura hispanoamericana en la Universidad de Chile, entidad tradicionalmente abierta a todos los requerimientos culturales en desarrollo; por ser político en el momento de alta tensión social surgido en la víspera de la Segunda Guerra; como por las especiales aptitudes de su vigorosa personalidad de escritor de oficio, consciente de un cometido específico, Ricardo Latcham era uno de los elementos más funcionales para cumplir con los propósitos de su generación.

Su labor literaria se inicia a los veinte años de edad, con artículos de crítica literaria, que ya no dejó de publicar hasta poco antes de su muerte, ocurrida en un breve viaje a Panamá, en revistas de Chile, de diveros países hispanoamericanos, de Estados Unidos y de España. Ellos suman una cantidad superior a los dos mil, en donde queda dispersa una visión viva del acontecer literario del continente, a los que será menester acudir cada vez que se intente un esfuerzo de ordenamiento y valoración del acervo creador de las letras americanas de los últimos decenios.

Todo enfoque crítico de Ricardo Latcham posee una suerte de rotundidad y entereza que convence y estimula, sin que su actitud aparezca dogmática o caprichosa. Ello se debe a algunos factores individualizadores de su personalidad, siempre atrayente para adversarios, amigos y, especialmente, para sus discípulos universitarios, quienes, por posiciones doc* 
trinarias encontradas, solían no estar de acuerdo con el maestro, pero lo sentían siempre como un seguro punto de referencia. Lo distinguía, en primer lugar, un criterio altamente independiente, sin sujeción a normas rutinarias, a un estilo $u$ otro compromiso que pudiera constreñir los alcances de su mirada objetiva y amplia. No vaciló en denunciar abiertamente, a través de los medios publicitarios de que disponía-cátedra, prensa y hasta la tertulia íntima- los males y defectos que descubría en libros o en orientaciones teóricas de sus propios partidarios políticos. Tampoco dejaba de poner de manifiesto, por los mismos vehículos de expresión, las debilidades humanas que creía advertir en sus compañeros, particularmente si se prestaban para formular un comentario ingeniosamente sarcástico que definía con relieves inolvidables una personalidad discutida o una institución cuya respetabilidad pudiera ser objeto de algún menoscabo.

Este individualismo, sin asomo de morbosidad, que Latcham cultivaba inconscientemente y que fluía de él más que como un rasgo negativo, como un aderezo de genio, acatado cordialmente por todos los que formaban el vasto círculo de sus adeptos, amigos y discífulos, hizo decır a Luis Durand, en sus recuerdos "Latcham, por ese tiempo, no obstante su terrible inquietud, era un excelente camarada. Un muchacho afectuoso a quien agradaba ir a visitar a sus amigos y estar con ellos, aunque jamás se preocupaba de oir lo que ellos decían, sino lo que él estaba hablando" (Gente de mi tiempo, Santiago-Chile, Nascimento, I953. p. 22). Más tarde circulaba otra especie amistosa, elaborada en el mismo tono que en estos casos empleaba el propio Latcham; sostenía que nuestro crítico gustaba siempre de ocupar el primer plano de la atención en una concurrencia, así en el bautizo deseaba ser el niño, en el casamiento la novia y en el entierro el difunto.

La agudeza de su espíritu crítico, finamente sensible a toda vibración de su ámbito, junto a su dinamismo mental contagioso, creaba en su torno una atmósfera de humor. Hay, sin embarg?, quienes no comprendieron su personalidad caracterizada por una vitalidad desbordante, siempre jovial, rasgos estimulantes que intepretaron como inestabilidad, desorden, mordacidad y corrosión. Es verdad, eso sí, que en el género polémico Latcham era temible y su ingenio para zaherir sutilmente era inagotable y original. Todavía se recuerdan páginas suyas escritas en este tono, en periódicos chilenos de batalla ideológica, como La Opinión, Indice y Wikén, semanario de barricada que él dirigió en momentos de 
álgida agitación social, y ha hecho famoso más de algún apodo con que, sintetizando el carácter de su adversario, lo bautizó para siempre.

Su espontaneidad incontenible en la exteriorización de su parecer, invariablemente honrado y sostenido en indiscutibles fundamentos, respecto de hombres, libros o entidades, y el vigor nervudo de incisivo humorismo con que lo expresaba, era esperado con el inquietante recelo de lo insólito. Cuando en I959 fue designado Embajador de Chile en Uruguay, ninguno de los que lo conocían le vaticinó una larga permanencia en ese cargo en el que la discresión y el cálculo juegan un papel tan básico. Pero a pesar de toda predicción, y sin que Latcham modificara su esencial modo de ser, se mantuvo incólume en ese medio neurálgico, cumpliendo exitosamente su misión durante cuatro largos años, en los que realizó una faena de profundo acercamiento cultural entre los dos países. Su labor fue reconocida en Montevideo por medio del nombramiento que la Universidad de la República hizo recaer en él de la Catedra América, distinción que no había sido otorgada desde el fallecimiento de José Enrique Rodó, en I9I7.

Otro de los factores que conferían solvencia al oficio de Ricardo Latcham era su posición de espectador vigilante, que reacciona con sano entusiasmo a toda traza de estímulos de importancia que se operan en el escenario cultural hispanoamericano. Leía en español, inglés, francés, portugués y catalán, con una velocidad monstruosa. La minuciosidad de esas lecturas era evidente; algunas de las piezas que pasaron por sus manos, llegadas eventualmente hasta nosotros (muchos de sus libros fueron legados por él al Instituto de Literatura Chilena) aparecen subrayadas con gruesos azules o rojos, que invariablemente destacan los sectores más felices del texto o aquellos desaciertos de mayor bulto; suelen agregarse breves comentarios marginales, indicación de omisiones o de errores. Esa enorme capacidad de lector acucioso le permitía, pues, mantener cómodamente al día en la producción literaria no sólo fundamental de todos los países del continente, sino en publicaciones menores de autores principiantes. A esta facundia de lecturas se agregaba su memoria asombrosa, que conservó hasta sus últimos días. Solía citar, en clases o tertulias, nombres de personajes literarios, de autores y datos bibliográficos, sin vacilación alguna y sin consultar anotaciones. Escribía - lo vimos muchas veces-directamente a la máquina; se detenía de vez en cuando y se enfrentaba a las estanterías de su inmensa biblioteca, y con segura precisión ubicaba el volumen que deseaba consultar, entre los millares que poseía cuidadosamente encuadernados. 
Su objetivismo riguroso, su afán encaminado a la búsqueda de lo que una obra posee de auténtico y valioso como expresión de una realidad claramente sentida, estaban vitalizados por un lenguaje vivo, ágil, lleno de comparaciones y referencias a otras obras y debidamente asociado al sistema creador en vigencia. Todo ello proporcionaba a su crítica una macicez y una gracia de vigorosos rasgos que superaba el virtuosismo impresionista de muchos escritores de cultura improvisada o algo atragantados con lecturas no bien digeridas de teóricos extranjeros. Su autoridad crítica estaba sustentada en un vasto fondo cultural orgánico, de base estética, sociológica e histórica. Su primer maestro fue su padre, el etnógrafo y arqueólogo Ricardo E. Latcham, de quien heredó, sin duda, la tendencia a la concreción de un pensamiento claro y a la forma directa de expresión, exenta del regodeo formal y digresivo que en otros solía convertir la crítica en un motivo de efusión personal. Es curioso anotar que, poseyendo Latcham un carácter de tan fuerte personalismo en su vida privada, se mostrara tan equilibradamente ecuánime en sus enfoques críticos; sobre todo frente a la producción de los jóvenes mostraba, por lo general, una actitud esperanzada y estimulante.

Completó su primera formación intelectual sistemática bajo las lecciones que recibió de maestros como Antonio Rubio y Lluch, en Barcelona, y de Américo Castro, en Madrid.

Después de publicar, en I925, la serie de ensayos que reunió bajo el sugestivo título de Escalpello, libro que reveló a un joven dueño de un bagaje documental extraordinario y de una energía expresiva desbordante, el autor intentó probar su vitalidad en la ficción, y dio a las prensas, en 1926 , la novela breve Vidas ardientes, que terminó por convencerlo que su destino en las letras no caía de lleno dentro de la línea de la creación pura; y el mismo año publicó su ensayo Chraquicamata, Estado ysnki; el primer planteo moderno del tema siempre latente relacionado con el problema de la nacionalización de la mayor fuente cuprífera de América.

$Y$ ya su ruta queda definitivamente encauzada hacia la literatura de ideas, actividad que destaca su nombre en el primer plano del escenario intelectual del continente. Mientras atiende sus cátedras de literatura en la Universidad de Chile, corporación en donde llegó a ocupar el cargo de Decano de la Facultad de Filosofía y Educación (r945-47), viaja por invitación de los centros culturales más notables y activos de 
las Américas, de España, Inglaterra, Francia y Checoslovaquia, en cuyas sedes dicta cursilles y conferencias sobre los valores literarios, históricos y sociológicos de América Hispana. En Madrid, por ejemplo, dicta un curso sobre la novela hispanoamericana contemporánea, al mismo tiempo que trabaja en la edición del poema barroco Ignacio de Cantabria, del poeta chileno Pedro de Oña, tarea que le fue encomendada por el Consejo Superior de Investigaciones Científicas de esa capital. Esta obra de Latcham, aún inédita, constituye uno de los primeros esfuerzos en la determinación fundada, de las proyecciones básicas del barroco en los escritores del Nuevo Mundo, a través del ciclo ignaciano, del que el poeta chileno es el representante más notable en estas latitudes.

La frecuentación personal de los centros culturales americanos, inclusive los de Brasil y de cuyos valores fue un entusiasta divulgador, y el conocimiento directo de sus fuentes poéticas, conferían a Ricardo Latcham una suerte de calidad de ciudadano de América y de uno de sus animadores de voz más ampliamente escuchada. En apoyo de esta afirmación pueden citarse, entre sus múltiples trabajos, tres de ellos en que culmina su envergadura de hombre profundamente inmerso en el desenvolvimiento y el destino de las letras hispanoamericanas. Primero, su ensayo sobre La Historia del Crállismo, I956, páginas fundamentales para establecer el origen, el desarrollo y la plenitud de esta corriente definidora de uno de los momentos más brillantes de la literatura continental. Luego su Antología del cuento bispanoamericano contemporáneo (1910-1956), publicada en 1958 , la más completa imagen de conjunto de la narrativa breve aparecida antes de los libros sobre la misma materia, de Angel Flores, al año siguiente, y de Seymour Menton, en 1964. El último libro de Latcham es Carnet Critico, 1962, formado por cuarenta artículos publicados entre los años 1950 y 196r, en La Nación, de Santiago de Chile, diario cuya sección de crítica literaria atendió desde I94I a I952, y luego de 1957 hasta sus últimos días; en El Nacional, de Caracas y en Marcha, de Montevideo. En esos artículos, el autor enjuicia la producción más significativa de los cuatro países que, en el decenio señalado, llevan el tono de vanguardia del proceso literario del continente: México, Venezuela, Uruguay y Chile.

La sólida base humanística de Ricardo Latcham, el conocimiento cabal que poseía de la historia y la literatura de América, y su capacidad para discernir entre lo absoluto y lo contingente, lo señalaban como uno 
de los espíritus mejor dotados para estructurar la Historia critica de la literatura bispanoamericana, libro que proyectaba publicar en varios volúmenes y que dejó a medio camino.

Julio Durán.Cerda

Universidad de Chile

The University of Arizona 
